\title{
C-12
}

\section{REDES SOSTENIBLES EN PVC ORIENTADO (PVC-O) HUELLA AMBIENTAL}

\author{
Martínez del Amo, Y (1) (P), Romero Montoya, M (2)
}

${ }^{1}$ Director Marketing y Certificación, Molecor, yolanda.martinez@molecor.com

${ }^{2}$ Técnico Infraestructuras Hidráulicas, Molecor, manel.romero@molecor.com

\section{1- Impacto ambiental de las Tuberías de PVC Orientado.}

El impacto ambiental de un sistema de tuberías depende de su composición y la aplicación de las mismas. Los factores que determinan la eficiencia durante todo el ciclo de vida de una tubería son principalmente: el tipo de materia prima utilizada, el proceso de producción, el acabado del producto, y su vida útil.

Las Tuberías de PVC-O se presentan como la solución más ecológica debido a su mejor contribución al correcto desarrollo sostenible del planeta, tal como demuestran diferentes estudios a nivel mundial. EI PVC-O presenta ventajas medioambientales en todas las fases de su ciclo de vida (figura 1):

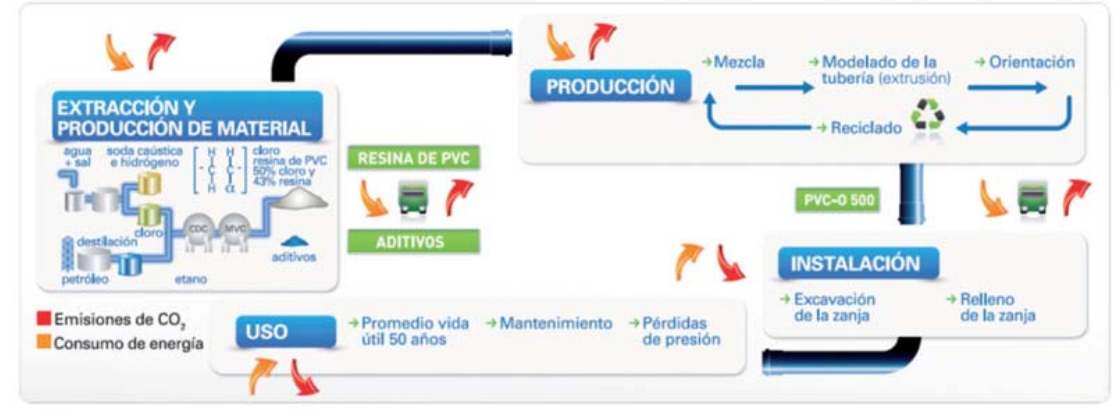

Figura 1. Ciclo de vida de las tuberías de PVC-O

\section{Eficiencia en Recursos Naturales}

- Petroleo. Sólo el 43\% de la composición del PVC depende del petróleo.

- Materias primas. Gracias a la mejora de propiedades que se consigue durante la orientación molecular, se puede utilizar menor cantidad de materia prima.

- Energía. Menor consumo en: extracción de la materia prima, fabricación de la tubería y en el uso.

\section{Eficiencia en la Gestión de Residuos}

EI PVC es un material 100\% reciclable que puede ser reutilizado en la fabricación de otras aplicaciones plásticas.

\section{Mejor Contribución a la Sostenibilidad}

- Menor huella de carbono. Por las menores emisiones de $\mathrm{CO}_{2}$ a la atmósfera según muestran diversos estudios internacionales.

- Menor huella ambiental. Según la declaración ambiental de producto (EPD), las tuberías de PVC-O presentan un menor impacto ambiental, no sólo en el calentamiento global, sino en otros 5 parámetros medioambientales.

\section{- $\underline{\text { Otros }}$}


- Optimización del transporte. Por su menor menos se puede transportar más cantidad de material, por tanto realizaremos ahorro de combustible

- Eficiencia en costes de instalación. Es más ligera y manejable que los tubos fabricados con otros materiales, con lo que se reduce la utilización de maquinaria.

\section{2- Directrices europeas sobre la Huella Ambiental.}

Desde la Unión Europea se está fomentando la correcta preservación del medioambiente. Por ejemplo, el Reglamento de Productos de Construcción como requisitos básicos en obras de construcción, requiere considerar: ahorro de energía, uso sostenible de los recursos naturales, durabilidad de las obras y respeto al medioambiente de los materiales utilizados.

En Europa se han desarrollado diversas metodologías de estudio del impacto ambiental, y desde la Comisión Europea, recopilando toda esta información, se ha lanzado la Recomendación 179/2013/CE relativa al cálculo de Huella Ambiental de Producto (HAPPEF). Está basada en el análisis del ciclo de vida del producto (ACV-LCA) y la evaluación de su impacto ambiental en diferentes parámetros ambientales.

Según ésta, se ha realizado el estudio de Huella Ambiental de la Tubería PVC Orientado clase 500. Este método está basado en el análisis del ciclo de vida (ACV) del producto a lo largo de todas las fases de cuna a tumba.

El cálculo se ha realizado con el software profesional Air.e LCA integrado con las bases de datos de Ecoinvent y ELCD, teniendo en cuenta además, la normativa aplicable sobre ciclo de vida y declaraciones ambientales del producto (EPD), y las metodologías IPCC 2007 e ILCD.

Así, se estiman 14 impactos ambientales que se agrupan en función de la afección a los distintos medios:

- Aire y atmósfera: Cambio climático, Acidificación, Agotamiento de la capa de ozono y Formación de ozono fotoquímico

- Agua: Agotamiento de recursos (agua), Ecotoxicidad del agua dulce y Eutrofización del agua

- Suelo: Agotamiento de recursos (minerales), Eutrofización terrestre y Uso del terreno

- Salud humana: Elementos respiratorios inorgánicos, Radiación ionizante, Efectos en la salud humana (cancerígenos) y Efectos en la salud humana (no cancerígenos)

La Huella de Carbono se obtiene del impacto Cambio Climático,

\section{3- Resultados estudio huella ambiental}

Los resultados obtenidos se muestran en la figura 2 


\begin{tabular}{|c|c|c|c|}
\hline & Abrolutos & & Normalizados \\
\hline Cambio climático: & $8.5 E+01$ & $\mathrm{~kg}$ de $\mathrm{CO} 2 \mathrm{e}$ & $9.5 \mathrm{E}-03$ \\
\hline Agotamiento de ozono & $4.8 \mathrm{E}-06$ & $\mathrm{~kg}$ CFC-11e & $2.2 E-04$ \\
\hline Ecotoxicidad agua dulce & $1.8 E+02$ & CTue & $2.1 \mathrm{E}-02$ \\
\hline $\begin{array}{l}\text { Efectos en la salud humana } \\
\text { (cancerigenos) }\end{array}$ & $4.8 E-06$ & crue & 1.3E-01 \\
\hline $\begin{array}{l}\text { Efectos en la salud humana (no } \\
\text { cancerigenos) }\end{array}$ & $8.5 E-06$ & cTun & $1.6 E-02$ \\
\hline Elementos respiratorios inorgánicos & $1.2 E-02$ & $\mathrm{~kg}$ PM2.5e & 2.7E-03 \\
\hline Radiación ionizante (humana) & $4.2 E+00$ & $\mathrm{~kg} \mathrm{U235e}$ & $3.7 E-03$ \\
\hline Formación ozono fotoquímico & 2.0E-01 & $\mathrm{kg} N M V O C$ & $6.3 E-03$ \\
\hline Acidificación & 2.4E.01 & molHte & $5.3 E-03$ \\
\hline Eutrofización terrestre & $8.4 E-02$ & mol Ne & $4.8 E-04$ \\
\hline Eutrofización agua dulce & $1.2 E-03$ & $\mathrm{~kg} P \mathrm{e}$ & 8.3E-04 \\
\hline Eutrofización agua marina & 4.6E-02 & $\mathrm{kg} \mathrm{Ne}$ & 2.7E-03 \\
\hline Agotamiento de recursos (agua) & $9.9 \mathrm{E}-01$ & $m^{3} S W U$ & $1.2 \mathrm{E}-02$ \\
\hline Agotamiento de recursos (minerales) & $5,7 E-03$ & $\mathrm{~kg}$ Sbe & $5.6 \mathrm{E}-02$ \\
\hline Uso del terreno & $2.7 E+02$ & $\mathrm{~kg}$ Cdet & $4.0 E-04$ \\
\hline
\end{tabular}

Figura 2. Resultados huella ambiental tuberías PVC-O clase 500

\section{4- Conclusiones.}

La orientación molecular otorga a las tuberías de PVC-O significativas ventajas en la calidad del producto, su instalación y uso. Ofrecen un mejor comportamiento de respeto al medioambiente, presentando una huella ambiental inferior a otros materiales (figura 3), mejorando la contribución al correcto desarrollo sostenible del planeta, y optimizando el consumo de recursos naturales.

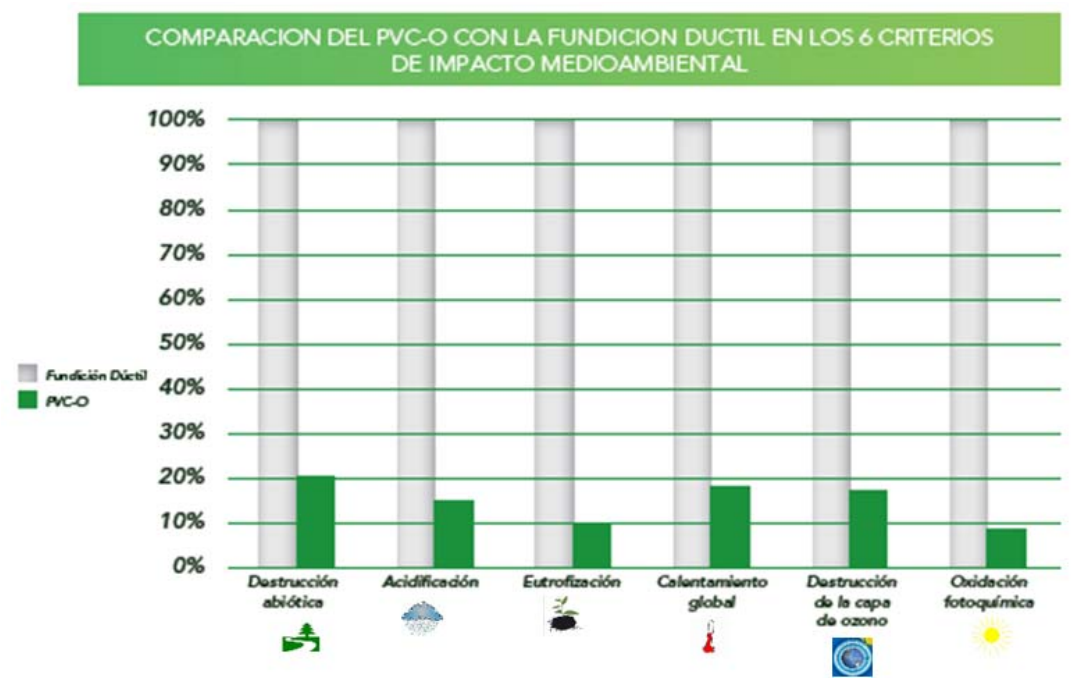

Figura 3. Comparación impacto ambiental PVC-O vs Fundición dúctil 